\title{
Double Pulse Modulation On Current Hamonic Suppression
}

\author{
LI Jun ${ }^{1, a}, \quad$ ZHANG Jun-hong ${ }^{2, b}$ and GAO Wei $i^{3 . c}$ \\ College of Electrical and information, Naval University of Engineering, China Wuhan \\ aMitsui86425@163.com '11960113@VIP.sina.com 'depkia@163.com
}

Key-words : DC-DC conversion, double-pulse modulation, current harmonic EMI

\begin{abstract}
Electromagnetic interference is now a hot research topic, in order to ensure reliable operation of the system, you must suppress EMI device from generating sources of electromagnetic interference suppression is more effective EMI suppression methods, through the use of double-pulse modulation, can effectively output current harmonics suppression, so as to achieve the purpose of suppressing EMI.
\end{abstract}

\section{Introduction}

Electromagnetic interference and electromagnetic compatibility design is now more popular research topic. Today's electronic products to increase the complexity of the system, some functional modules susceptible to EMI, to ensure reliable operation of the system must be defined EMI limits. According to the test of experience, DC-DC converter on the switching frequency energy spikes often exceed limits affect reliable operation of the system, but there is a huge switching frequency of peripheral margin. Therefore, the phenomenon is very valuable.

From the source to reduce the EMI noise suppressing EMI noise source itself (rather than suppress the EMI generated), you can prevent EMI interference filter plus auxiliary circuits generated. The double-pulse modulation to meet this requirement, the double-pulse modulation with conventional single-pulse modulation compared with the output current spread spectrum can speak achieve harmonic suppression purposes.

In this paper, Buck circuit as the prototype, we compare the current ripple under single pulse modulation with double pulse modulation, by schematics, formula derivation and simulation, finally, the double-pulse modulation can be demonstrated effectively suppress the current harmonic.

\section{Theoretical analysis}

First ,we described the principle of single pulse modulation as follows. Figure 1 shows the schematic:

From the principle illustrated in Figure1 we can deduce adjusted output single pulse mode current expression:

$$
\begin{array}{r}
i_{L}(t)=\left\{\begin{array}{r}
i_{L_{d}}+k_{1} t ; t \in\left[0, t_{e}\right] \\
i_{L_{d}}+k_{1} t_{e}-k_{2}\left(t-t_{e}\right) ; t \in\left(t_{e}, t_{e}+t_{f}\right]
\end{array}\right. \\
\operatorname{and} k_{1}=\frac{\Delta I_{L}}{D T_{S}}, k_{2}=\frac{\Delta I_{L}}{(1-D) T_{S}} \\
\Delta I_{L}=\frac{V_{S} D(1-D)}{L f_{S}}=k_{1} t_{e}
\end{array}
$$




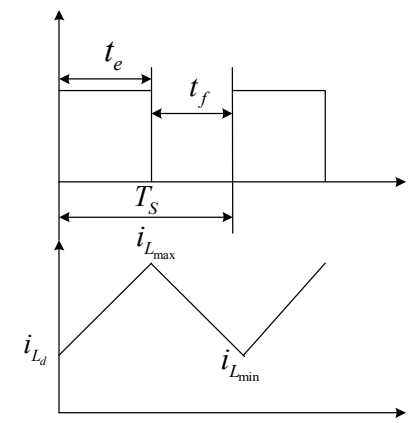

Figure 1 The principle schematic of single pulse modulation In a double-pulse modulation cycle, according to the formula (3), We can get: Two pulse current rise and fall rates are the same, double-pulse modulation method is as follows.

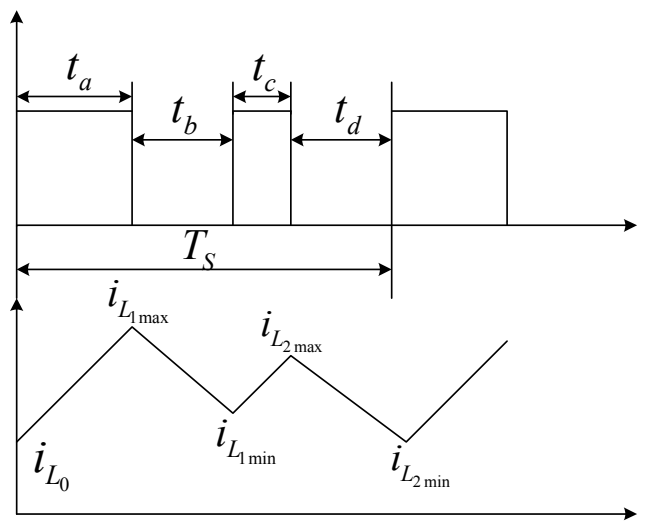

Figure 2 The principle schematic of double pulse modulation

Double pulse modulation current expression is as follows:

$$
i_{L}(t)=\left\{\begin{array}{l}
i_{L_{0}}+k_{1} t ; t \in\left[0, t_{a}\right] \\
i_{L_{0}}+k_{1} t_{a}-k_{2}\left(t-t_{a}\right) ; t \in\left(t_{a}, t_{a}+t_{b}\right] \\
i_{L_{0}}+k_{1} t_{a}-k_{2} t_{b}+k_{1}\left(t-t_{a}-t_{b}\right) ; t \in\left(t_{a}+t_{b}, t_{a}+t_{b}+t_{c}\right] \\
i_{L_{0}}+k_{1} t_{a}-k_{2} t_{b}+k_{1} t_{c}-k_{2}\left(t-t_{a}-t_{b}-t_{c}\right) ; t \in\left(t_{a}+t_{b}+t_{c}, t_{a}+t_{b}+t_{c}+t_{d}\right]
\end{array}\right.
$$

$$
\text { besides } t_{e}=t_{a}+t_{c}, t_{f}=t_{b}+t_{d}
$$

We can get a single pulse modulation of the expression of the current harmonics, $i_{L}(t)=\frac{a_{0}}{2}+\sum_{n=1}^{\infty} a_{n} \cos (n \Omega t)+\sum_{n=1}^{\infty} b_{n} \sin (n \Omega t)(6)$

$i_{L}(t)=\frac{a_{0}}{2}+\sum_{n=1}^{\infty} A_{n} \sin \left(n \Omega t+\varphi_{n}\right)$

$A_{n}=\sqrt{a_{n}^{2}+b_{n}^{2}}, \quad \varphi_{n}=\arctan \frac{a_{n}}{b_{n}}(8)$

$\varphi_{n}=\arctan \frac{\cos \left(n \Omega t_{e}\right)-1}{\sin \left(n \Omega t_{e}\right)}, \quad A_{n}=\frac{\Delta I_{L} T^{2}\left|\sin \left(n \Omega t_{e}\right)\right|}{n^{2} t_{e} t_{f} \pi^{2}}(9)$

Double pulse modulated current harmonics: $\quad \varphi_{n}=\arctan \frac{\cos \left(n \Omega t_{a}\right)+\cos \left[n \Omega\left(t_{a}+t_{b}+t_{c}\right)\right]-1-\cos \left[n \Omega\left(t_{a}+t_{b}\right)\right]}{\sin \left(n \Omega t_{a}\right)+\sin \left[n \Omega\left(t_{a}+t_{b}+t_{c}\right)\right]-\sin \left[n \Omega\left(t_{a}+t_{b}\right)\right.}$

$A_{n}=\frac{4}{T} \frac{\left(k_{1}+k_{2}\right)}{n^{2} \Omega^{2}} \sqrt{\begin{array}{l}\sin ^{2}\left(n \pi D_{o n_{1}}\right)+\sin ^{2}\left[n \pi\left(D+D_{o f f_{1}}\right)+\sin ^{2}\left(n \pi D_{o f f_{1}}\right)+\sin ^{2}\left[n \pi\left(D-D_{o n_{1}}\right)\right]-\right. \\ \sin ^{2}\left[n \pi\left(D+D_{o f f_{1}}-D_{o n_{1}}\right)\right]-\sin ^{2}\left[n \pi\left(D_{o n_{1}}+D_{o f f_{1}}\right)\right]\end{array}}$ 
$A_{n}^{\prime}=\sqrt{\begin{array}{l}\sin ^{2}\left(n \pi D_{o n_{1}}\right)+\sin ^{2}\left[n \pi\left(D+D_{o f f_{1}}\right)+\sin ^{2}\left(n \pi D_{o f f_{1}}\right)+\sin ^{2}\left[n \pi\left(D-D_{o n_{1}}\right)\right]-\right. \\ \sin ^{2}\left[n \pi\left(D+D_{o f f_{1}}-D_{o n_{1}}\right)\right]-\sin ^{2}\left[n \pi\left(D_{o n_{1}}+D_{o f f_{1}}\right)\right]\end{array}}$

\section{Simulation Analysis}

In order to verify the double pulse modulation can be a current harmonics suppression, we double-pulse modulation output current harmonic simulation analysis in this paper to analyze the 5th harmonic,Buck circuit as the prototype, Circuit parameters are as follows : $V_{S}=48 \mathrm{~V}, D=0.5, f_{s}=50 \mathrm{kHz}, R=2.2 \Omega$ The figure3 is the relation between $A_{n}^{\prime}$ and $D_{o n l}, D_{o f f l}$.

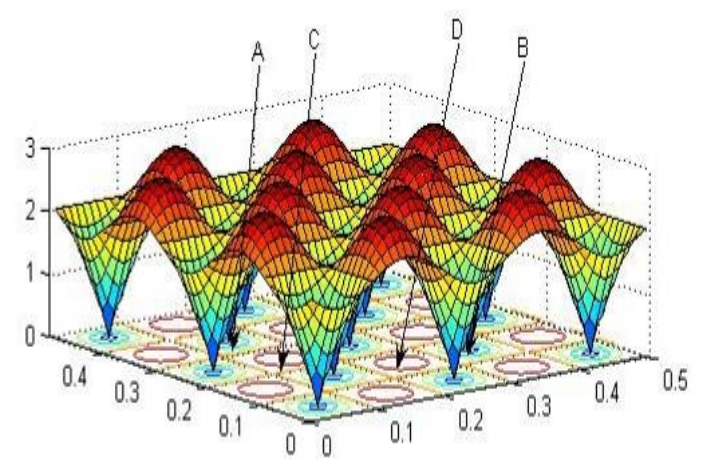

Figure3 The relation between $A_{n}^{\prime}$ and $D_{o n l}, D_{o f f}$

From the figure, we can see the fifth harmonic of the Minimax place, we spot a few Minimax simulation analysis:
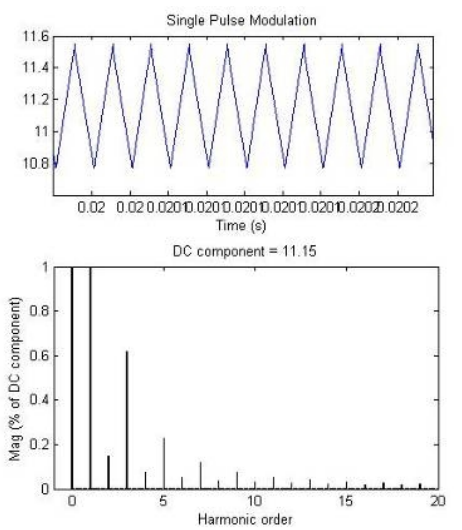

Figure 4 The current harmonic of single pulse modulation

Through the simulation results in Figure 4 and Figure 5, we can see, change $D_{o n l}$ and $D_{\text {off } 1}$ can change the amplitude of the current harmonics, And the simulation results corresponding to Figure 3 minimax points. And compared with a single pulse modulation, a current harmonics significantly suppressed.
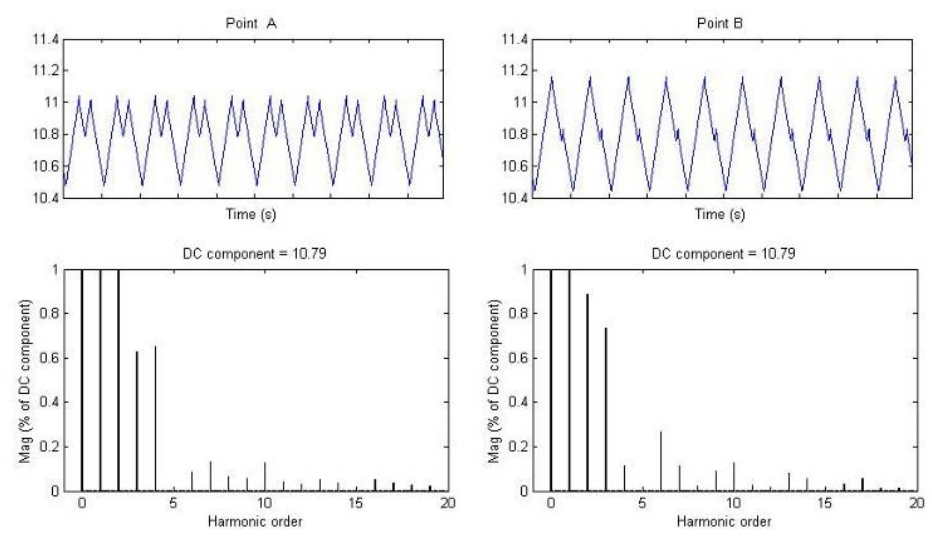

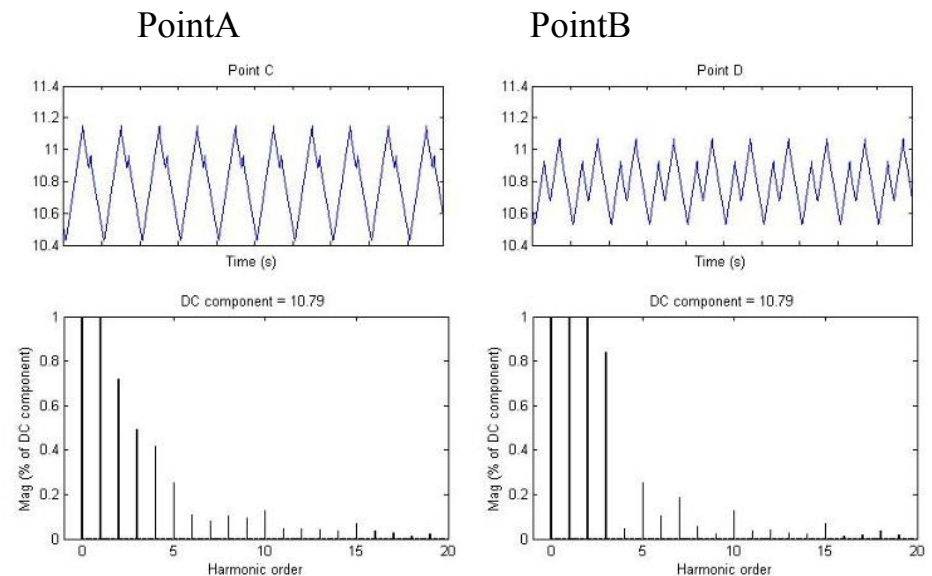

PointC

PointD

Figure 5 The current harmonic of double pulse modulation

\section{Conclusion}

In this paper, Buck circuit as the prototype, we compare the current ripple under single pulse modulation with double pulse modulation, by schematics, formula derivation and simulation, finally, the double-pulse modulation can be demonstrated effectively suppress the current harmonic.

\section{References}

1. [1]Q. Zhaoming, W. Xin, and L. Zhengyu, "Status of electromagnetic compatibility research in power electronics," in Proc. Int. Power Electron. Motion Control Conf.,2000,pp.46-57.

2. [2]R.Chen, J.D.vanWyk, S.Wang, and W.G.Odendaal, "Technologies and Characteristics of integrated EMI filters for switch mode power supplies," in Proc. IEEE Power Electron.Spec.Conf.,2004, vol.6, pp.4873-4880.

3. [3]R.Chen, J.D.vanWyk, S.Wang, and W.G.Odendaal, "Planar electromagnetic integration technologies for integrated EMI filters," in Proc. IEEE IAS Annu. Meeting Ind. Appl. Conf., 2003,pp.1582-1588.

4. [4]L.E.LaWhite and M.F.Schlecht, "Active filters for $1 \mathrm{MHz}$ power circuits with strict input/output ripple requirements," in Proc. IEEE Power Electron. Spec. Conf. ,1986,pp.255-263.

5. [5]N.K.Poon, J.C.P.Liu, C.K.Tse, and M.H.Pong, "Techniques for input ripple current cancellation: Classification and implementation," IEEE Trans.PowerElectron.,vol. 15, no. 6,pp.1144-1152,Nov. 2000. 